\title{
VIAJAR POR LA MAR DEL SUR... DE TOPONIMIA Y CARTOGRAFÍA HISTÓRICA ${ }^{\alpha}$
}

\section{Traveling the South Sea ... Of toponymy and historical cartography}

\section{María Esther Aguirre Lora ${ }^{\beta}$}

Fecha de recepción: 03/07/2020 • Fecha de aceptación: 21/10/2020

Resumen: El propósito de este texto es aproximarse a un territorio que resulta muy atractivo, el de las Californias, que desde sus orígenes ha estado envuelto en historias fascinantes que quedarían grabadas, en principio, en la memoria colectiva y en el orgullo de los habitantes de la región, en los imaginarios heredados en el propio nombre, pero que también cobran cuerpo en sus progresivas expresiones cartográficas en el curso de los siglos, contrariamente a la imagen fija, estática, que pudieran ofrecer las representaciones iconográficas cristalizadas en sus sucesivos mapas, así como los nombres de la región en boga, ajenos a las historias que los contienen. Cartografía histórica y toponimia son las dos dimensiones que se exploran en este texto, ilustradas con el caso de las Californias, y que sugerimos integrar en el aprendizaje de los saberes geográficos.

Palabras clave: California; toponimia; cartografía histórica; construcción del espacio; geografía crítica.

Abstract: The purpose of this text is to approach an especially attractive territory, that of the Californias, which since its origins has been the setting for fascinating stories. These accounts have for the most part remained in the collective memory of the inhabitants of the region, constituting for them a source of pride and contributing to the imaginary inherent to the region's name itself. The lore figures into the area's changing cartographic expressions over

\footnotetext{
${ }^{\alpha}$ El presente texto constituye uno de los productos parciales del proyecto de investigación «Italianos en México. Producción y conservación del conocimiento, siglos XVI al XVIII, primera fase», con sede en el IISUE, UNAM.

B Instituto de Investigaciones sobre la Universidad y la Educación, UNAM. Lado norte de la Sala de Conciertos Nezahualcóyotl, Centro Cultural Universitario, Alcaldía Coyoacán, 04510, Ciudad de México (México). mariaestheraguirre@gmail.com / lora@unam.mx. (i) https://orcid.org/0000-00031261-8863
} 
the centuries, belying the fixed, static image suggested by the crystallized iconographic representations of successive maps as well as the changing names of the region, and their obliviousness to the stories contained in them. Thus, this text delves into the dimensions of historical cartography and toponymy to examinethe case of the Californias, an instance that we suggest be integrated into the learning of geographical knowledge.

Keywords: California; toponymy; historical cartography; construction of space; critical geography.

El nombre del lugar es a la vez propiedad de todos y de nadie. Si hay que hablar en cualquier caso de pertenencia hay que referirse a la memoria colectiva. Tal nombre es tomado en préstamo por sus usuarios, con la particularidad de que el uso puede modificar el objeto del préstamo. En definitiva, el nombre de lugar es antes que nada un modo de comunicación y un testimonio del contexto de su origen, de sus transformaciones y de todo aquello que tales transformaciones atestiguan.

Henri Dorion.

\section{CONTEXTUANDO}

Las Californias, si bien se trataba de la región que abarcaba el suroeste de la Unión Americana (estado de California, parte de Nevada, Utah, Arizona y Wyoming) y la península de Baja California, se trata más bien de la Antigua California, la original, la del siglo XVI, la de los primeros misioneros, en su mayoría españoles, que a ella llegaron, región que desde un principio fue ajustándose a las transformaciones e intereses de los tiempos: ya desde los tiempos de los Jesuitas, la zona se dividió, para facilitar su manejo, en lo que era la Antigua California y la Alta o Nueva California, que abarcaba una zona más amplia (actual noroeste del país y suroeste de la Unión Americana). Para 1772, una vez que los jesuitas habían sido expulsados de la Nueva España (1767), el virrey Bucareli estableció en 1773 un acuerdo entre las órdenes misioneras que recorrían lo que fuera la región de las misiones jesuíticas del noroeste del país, asignando a los dominicos la zona del sur, la Vieja California, y a los franciscanos la zona del norte, la Alta o Nueva California, sin que ambas dejaran de pertenecer a la Nueva España; los jesuitas habían tenido la intención de renombrarla Las Carolinas en honor al rey Carlos II, 
solo que esto ya no se logró porque coincidió con su expulsión. ${ }^{1}$ Con la guerra de intervención de los Estados Unidos (1846-1848), México perdió aproximadamente $2.378 .539 \mathrm{~km}^{2}$ del territorio nacional que abarcaban la Alta California, Nuevo México y Texas, regiones que el gobierno de los Estado Unidos, desde tiempos del Virreinato de la Nueva España, estaba interesado en adquirir. La Antigua California, en posesión de México, se dividió en la del sur y la del norte, con el nombre de Baja California.

\section{NOTAS SOBRE LA GEOGRAFÍA Y SU APRENDIZAJE}

Uno de los saberes de antigua data, imprescindibles en las tareas del gobierno de los territorios, como cuerpos de saberes estratégicos en estrecha relación con el conocimiento del territorio para su defensa y explotación, por lo demás, profundamente vinculados con la formación de la identidad colectiva de los mexicanos en el contexto de la construcción de la Nación Mexicana, han sido la geografía y la estadística. Saberes, por otra parte, que si bien se vincularon directamente, a horcajadas de los siglos XVIII y XIX, con la formación altamente especializada de los ingenieros y militares, paulatinamente, con muchas dificultades, emigraron a la escuela popular como disciplina de estudio, al lado de la lectura, la escritura, la aritmética, la historia, las ciencias naturales, entre otros campos del saber.

La enseñanza de la geografía se fue replanteando al ritmo de la pedagogía moderna, de la escuela nueva, de los constructivismos, hasta llegar, en el momento actual, a dar cuenta de un campo de tensión en el que confluyen tendencias divergentes que pueden enmarcarse en la geografía tradicional y la geografía renovada. ${ }^{2}$ La primera, que naturaliza el espacio volviendo neutral cualquier representación que se haga de él, a menudo presenta una tendencia enciclopédica en la que se acumulan datos y más datos mediados para su enseñanza por su memorización, siempre desde la perspectiva de la enumeración y descripción objetiva

\footnotetext{
1 "Memorial del Padre Juan María de Salvatierra a la Real Audiencia de México», $1^{\circ}$ de marzo de 1700. Fondo Misiones Jesuíticas, 3/42.3. Archivo Franciscano, Biblioteca Nacional; Miguel León-Portilla, Cartografía y crónicas de la Antigua California (México: UNAM, 1989), 35-38.

2 José Armando Santiago Rivera, «La enseñanza geográfica tradicional, la renovación pedagógica y didáctica de su práctica escolar cotidiana», Terra 30, n. ${ }^{\circ} 48$ (2014): 63-81.
} 
de los hechos y fenómenos, la localización de lugares sin ir más allá. La segunda, que destaca el espacio-territorio como construcción cultural, social y simbólica, se plantea procesos de comprensión de las problemáticas sociales y ambientales que entren en juego, con un importante valor formativo, y atiende a la historicidad de los fenómenos en una perspectiva de largo aliento que incida en la explicación del momento presente, lo cual propicia el acercamiento al territorio, al espacio como una construcción social, humana, ${ }^{3}$ que daría como resultado una perspectiva crítica.

En este contexto, nuestra apuesta es que uno de los recursos para problematizar las representaciones geográficas, como expresión de la realidad sin más que se dan por hechas y fijadas a lo largo del tiempo, pueden ser la toponimia y la cartografía histórica, en la medida en que permiten comprender el carácter relativo de dichas representaciones y su condición de construcción histórico-cultural en la que intervienen personas y grupos a lo largo del tiempo: es así como los mapas, como representación gráfica del espacio, de ningún modo son neutrales. La definición y configuración de los mapas, en el curso del tiempo, pueden verse influidas por varios factores que van tanto desde las posibilidades o limitaciones propias del momento como por motivos de intereses políticos. De modo que en la condición interdisciplinar que exige el estudio de la geografía, la historiografía, en la vertiente de historia cultural, ofrece un recurso imprescindible para develar los procesos implícitos en la construcción de los mapas y la manera en que han participado en ello las distintas comunidades en el curso del tiempo. Al respecto, resulta ilustrador el título del libro de Mark Monmonier, How to lie with maps (Chicago: University of Chicago Press, 1991).

Por su parte, la toponimia también resulta una perspectiva nuclear que se proyecta en la manera en que construimos el espacio; convoca la urdimbre del imaginario colectivo en torno a los nombres de las regiones, del paisaje geográfico, nombres que constituimos y que nos constituyen de modo indisociable. Los nombres de los lugares están estrechamente entramados con la historia y la cultura de sus habitantes; ${ }^{4}$

\footnotetext{
${ }^{3}$ Brenda L. Murphy, «From interdisciplinary to inter-epistemological approaches: Con-fronting the challenges of integrated climate change research", Canadian Geographer 55, n. 4 (2011): 490-509.

${ }^{4}$ Eduardo Bedoya, «Toponimia: Herencia cultural», Revista Herencia 19, n. ${ }^{1}$ (2006): 9-31.
} 
constituyen un ingrediente central en la construcción de las identidades colectivas, en algunos casos más que en otros, en la medida en que en esos «nombres» de los territorios también se juega la memoria y el olvido.

Nuevamente es la historia cultural y otras perspectivas de las ciencias humanas como la antropología cultural, las que hurgan en la memoria colectiva, no solo como conocimiento del pasado por sí mismo, sino por su estrecha relación con los imaginarios que se han proyectado a la sociedad actual, mediados por la carga intergeneracional puesta en los procesos de la construcción simbólica de los espacios, de los lugares, de la manera en que los han nombrado. ${ }^{5}$

De hecho, los topónimos, o los nombres de los lugares, forman parte de nuestro patrimonio histórico-cultural y, si en un primer análisis expresan los usos lingüísticos de la región, también contienen historias entramadas que resguardan la memoria colectiva y que marcan la identidad de los pobladores; en ellos la lingüística se cruza con la geografía, con la historia y con otras múltiples dimensiones. Resulta interesante señalar que los topónimos surgieron a finales del siglo XIX vinculados con la compilación de la literatura y el folclor donde, poco a poco, se sintió la necesidad de conocer el origen de los nombres de algunos lugares y la manera en que sus habitantes se identifican con él.

\section{CALIFORNIA, EN EL NOMBRE, UN ORIGEN LEJANO}

Sus historias se tejen entre la alta Edad Media y el Renacimiento, a horcajadas de los siglos XIII y XIV, en medio de las aventuras de los caballeros andantes, quienes, a imitación de los héroes griegos, hacían gala de su comportamiento virtuoso y lograban méritos, movidos por el anhelo de labrarse un destino conquistando un lugar en la historia. Recorrían el mundo venciendo a sus enemigos y superando cuanto obstáculo se les presentaba para lograr un mundo mejor. De ahí surgieron los

\footnotetext{
${ }_{5}^{5} \mathrm{Si}$ bien la memoria colectiva es un concepto que se abrió paso alrededor de los años veinte del siglo XX con la ahora clásica obra de Maurice Halbawchs, habremos de esperar a la década de los ochenta para presenciar el giro memorialístico. A partir de esta perspectiva el horizonte disciplinar se amplió y enriqueció dando cabida a temáticas sugerentes que han aportado a la comprensión de lo social en la medida en que han emergido elementos sobre los modos en que individuos, grupos y comunidades procesan los recuerdos y olvidos directamente vinculados con la construcción de imaginarios y la definición de identidades individuales y colectivas.
} 
libros de caballería, que constituyeron un género literario muy apreciado particularmente en la España de los siglos XV y XVI. Y es precisamente en uno de los más valorados libros, el Amadís de Gaula (Zaragoza, 1508), procedente de la tradición bretona, cuyos episodios ocurren en tiempos del Rey Arturo, donde se narran las aventuras de un caballero andante por la Gran Bretaña; se trata de un libro con amplia circulación en España, editado por Cromberger en Sevilla, lugar del que partían las naves para la Nueva España. La obra, cuya autoría se atribuyó a Garci Rodríguez de Montalvo, se desarrolló inicialmente en cuatro libros, a la que se le integró un quinto libro de caballería, Las sergas del muy esforzado caballero de Esplandián (Sevilla: Cromberger, 1510), que remite a las hazañas de Esplandián, uno de los hijos de Amadís y de la princesa Oriana. El relato gira en torno al viaje de los caballeros desde Constantinopla hasta California; es precisamente en él, donde encontramos el nombre de California referido a una isla maravillosa:

Sabed que a la diestra mano de las Indias hubo una Isla llamada California, muy llegada a la parte del Paraíso Terrenal, la cual fue poblada de mujeres negras, sin que algún varón entre ellas hubiese, que casi como las amazonas era su estilo de vivir. Ellas eran de valientes cuerpos y esforzados y ardientes corazones, y de grandes fuerzas. La ínsula en sí la más fuerte de riscos y bravas peñas que en el mundo se hallaba. Sus armas eran todas de oro, también las guarniciones de las bestias fieras, en que después de haber amansado cabalgaban, que en toda la Isla no había otro metal alguno. Y algunas veces que tenían paces con sus contrarios había ayuntamientos carnales, de donde se seguía quedar muchas de ellas preñadas, si parían hembra, guardábanla, y si parían varón luego era muerto... ${ }^{6}$

El relato se inscribe en las tradiciones y creencias medievales referidas a lo que estaba más allá, en el mar desconocido, poblado de míticas islas, misteriosas, y seres fantásticos donde abundaban el oro, las perlas, las piedras preciosas y también había mujeres hermosas y negras (lo cual indica su diferencia respecto de las mujeres blancas, es decir, a las mujeres negras sí se les puede agregar valentía, esfuerzo y «ardientes

\footnotetext{
6 «Cap. CLVII», en Garci Rodríguez de Montalvo, Las Sergas del muy virtuoso y esforzado caballero
} Esplandián, hijo de Amadís de Gaula (Sevilla: Cromberger, 1510), 100. 
corazones»), y que darían lugar a la imaginería de leyendas tales como El Dorado, la Atlántida, Arcadia, de los reinos de Quivira, Tiguez, las siete ciudades de Cíbola y el estrecho de Anián, entre otras: los territorios americanos eran una auténtica incógnita y despertaban la imaginación de quienes se atrevían a ir hacia ellos, de modo que para los hombres de mar no resultaría difícil mezclar realidad con fantasía.

Pues bien, el Amadís y Esplandián nos colocan frente al origen del nombre de los topónimos de dos de las actuales regiones representativas para los imaginarios sobre la América Latina: California y Amazonas; son mitos cuyo origen se ubica en Asia Menor y que, atravesando la Edad Media, se revitalizan hacia el siglo XVI para formar parte del imaginario de los exploradores, conquistadores y evangelizadores.

Con respecto a la lectura y la circulación de los libros de caballería entre los que se aventuraron a atravesar el mar, es importante reconsiderar los prejuicios generalizados sobre los conquistadores del siglo XVI como ignorantes y burdos; en realidad algunos de los castellanos que fueron a la Nueva España sabían leer, e incluso habían pisado la Universidad, como Hernán Cortés; fueron unos personajes peculiares, cuya imaginación estaba marcada por las mitologías y creencias medievales, de modo que se aventuraron a cruzar el mar tenebroso o la mar océana (Océano Atlántico) para encontrar monstruos, prodigios, seres fantásticos, maravillosos e inauditos nutridos por los bestiarios medievales, ${ }^{7}$ por la Historia natural de Plinio (23-79), o la Monstrorum Historia de Aldrovandi (1642), y por los relatos fabulosos que se transmitían en forma oral. América representaba la posibilidad de confrontarse con todo tipo de mirabilia.

Con respecto a la cultura escrita, es importante no perder de vista que la gran masa de la población europea, y española en este caso, prácticamente era analfabeta o estaba escasamente alfabetizada y la lectura en voz alta resultó ser una de sus prácticas culturales frecuentes realizada en grupo, ya fuera en iglesias, plazas públicas, en el refectorio de los monasterios o en los mesones. En el caso de la soldadesca que vino a tierras americanas, según el conocimiento de los usuarios, es posible

\footnotetext{
7 Carlos Alberto González Sánchez, Los mundos del libro. Medios de difusión de la cultura occidental en las Indias de los siglos XVI y XVII (Sevilla: Universidad de Sevilla-Diputación de Sevilla, 2001), 22-26.
} 
que leyeran de manera individual o en los usuales corrillos que se improvisaban en distintos lugares. ${ }^{8}$

De tal modo, los libros de caballería les abrirían a los exploradores nuevos horizontes. Vivieron el momento de la expansión de la imprenta en España donde la literatura fue más allá del ámbito religioso y de la lengua latina, para avocarse también a la impresión de literatura popular, escrita en lengua vernácula, en la que los libros favoritos fueron los de caballería.

Tampoco hay que perder de vista que las Sergas se imprimieron en Sevilla en 1510, en casa del editor Cromberger como ya mencionamos (quien, por cierto, fue el maestro del taller donde el impresor Giovanni Paoli trabajó en Sevilla y después fundó la primera imprenta americana en la Nueva España), lo cual facilitó el acceso a su lectura.

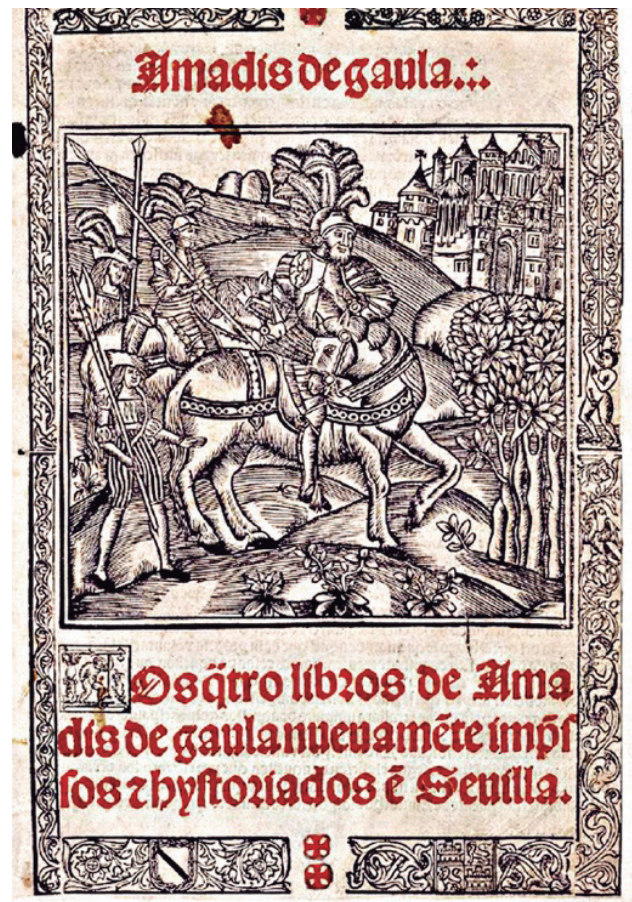

Garci Rodríguez de Montalvo, Amadis de Gaula (Sevilla, 1510

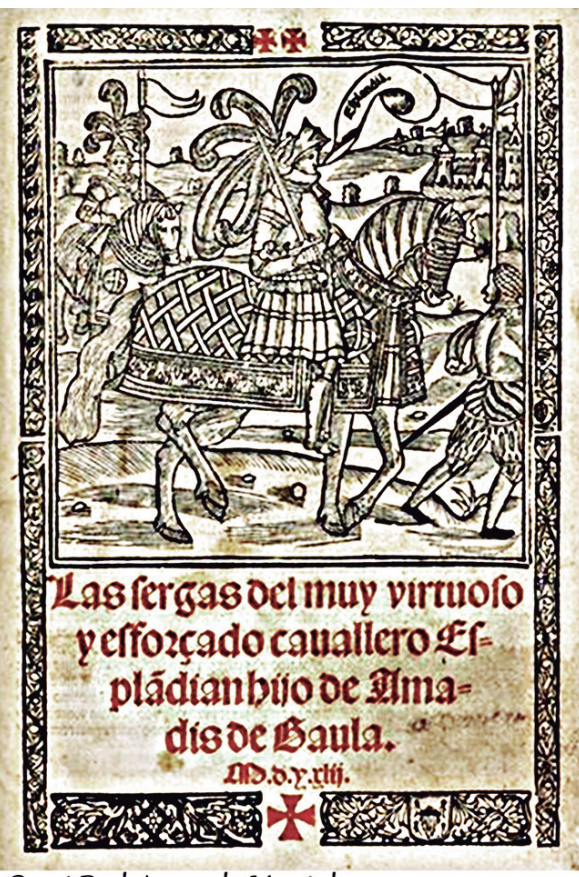

Garci Rodríguez de Montalvo,

Las sergas de Esplandián (Sevilla, 1510)

Figuras 1 y 2. Garci Rodríguez de Montalvo, Amadis de Gaula (Sevilla: Cromberger, 1510) y Las sergas de Espaldián (Sevilla: Cromberger, 1510).

\footnotetext{
${ }^{8}$ La investigación que al respecto hizo Irving A Leonard en Los libros del conquistador (México D. F.: Fondo de Cultura Económica, 1979, 2ª edición) es muy sugerente e ilustradora.
} 
Sin embargo, este tipo de literatura, que hacía perder los límites entre la fantasía y la realidad, no estuvo exenta de críticas y persecuciones por parte de moralistas y pensadores llegando al extremo de prohibir las historias mentirosas con base en la Cédula emitida por Carlos I en 1531 y ratificada en 1534, 1536 y en años posteriores, vetando la impresión y el envío a las Indias de «libros de romance, de historias vanas o de profanidad como son los Amadís y otros de esta calidad, porque este es mal ejercicio para los indios, e cosa en que no es bien que se ocupen y lean», 9 pues se trataba de un género literario desprestigiado por su carácter fantasioso, que se colocaba en el otro extremo de los fabulosos relatos bíblicos que ahora se querían introducir, y no faltó quien lo leyera o escuchara como si se tratara de una crónica referida a eventos ciertos. La disposición de las Cédulas, por supuesto, no tuvo efecto en el mercado librero que se estaba configurando.

Por otra parte, hay otros referentes que nos permiten entender quiénes fueron los primeros exploradores y conquistadores de nuestras regiones, quienes integran un abigarrado conjunto: parten con una fuerte tradición medieval en la que se juega la apuesta por la fama y la fortuna, en medio de las pruebas de distinto calibre que habría que enfrentar, para mejorar la propia condición. Lo cierto es que las cosas cambiaron y algunas para el reinado de Felipe II (1556-1598) resultaban obsoletas; eran los hidalgos quienes o lograban integrarse a los nuevos cuerpos de defensa del rey, o se mantenían dentro del grupo de clérigos y seglares con estudios universitarios, o bien se aventuraban a viajar a las Indias. Mediaba en ello la añoranza por las aventuras y odiseas narradas en los libros de caballería y la fantasía de poderse sumergir en mundos maravillosos poblados de seres fantásticos y fantásticas y colmados de riquezas jamás imaginadas. En este sentido, la literatura caballeresca y los relatos transmitidos de boca en boca, de quienes habían pisado tierras americanas, fertilizaban aún más su imaginación y los hacían vivirse como los protagonistas de las aventuras americanas, a la manera de los caballeros andantes que tenían frente a sí la gran oportunidad del meritazgo y la fortuna. Irving A. Leonard, los retrata muy bien:

Para los españoles, todos los informes que respondían a sus deseos y a sus preconcebidas nociones eran dignos de creerse; así,

\footnotetext{
${ }_{9}$ González Sánchez, Los mundos del libro, 68.
} 
con la imaginación inflamada por los libros de caballería, y concebidos por la aparente corroboración que los nativos daban a la existencia de los lugares encantados en el Nuevo Mundo, los rudos aventureros se insuflaban ánimos y se crecían hasta sentirse impulsados a sobrepasar los hechos estupendos de los caballeros andantes. Los sedentarios novelistas de España, Portugal y Francia no calcularon hasta qué extremo serían responsables de la conquista del Nuevo Mundo. ${ }^{10}$

También hay que tomar en cuenta que el interés de conquistadores y exploradores, una vez superada la etapa inicial de encuentro con el otro y del deslumbramiento de las riquezas del lugar, se dirigió a poblar la región en el más amplio sentido del término lo cual también aseguraba el patrimonio de sus descendientes.

Ahora bien, la exploración del Mar del Sur (hoy, Océano Pacífico) ${ }^{11}$ empezó muy temprano, a escasos años de la derrota de la Gran Tenochtitlan. Fueron los capitanes de Cortés quienes, a la vuelta de pocos años, exploraron la zona y en 1523 llegaron a lo que se pensó era la isla de Cihuatán (lugar poblado de mujeres), rica en oro y perlas. Gonzalo de Sandoval describió la zona casi con las mismas palabras del párrafo de Esplandián que se señaló arriba, ${ }^{12}$ aunque también se imbricó con antiguas creencias mesoamericanas que ubicaban un lugar

\footnotetext{
${ }^{10}$ Leonard, Los libros del conquistador, 47.

${ }_{11}$ El actual Océano Pacífico, en el curso de los primeros viajes de descubrimiento de los españoles, fue conocido como Mar del Sur o Mar de Balboa, ya sea por su posición en relación con el Mar del Caribe, que lo situaba al oriente del istmo de Panamá, hacia el sur, o bien por el nombre de su descubridor Vasco Núñez de Balboa en el contexto del Imperio español, alrededor de 1513. La denominación Mar del Sur se mantuvo hasta que Fernando de Magallanes, al navegar por sus aguas lo rebautizó como Mar Pacífico, por lo favorable que sus aguas resultaron para la navegación. Mar del Sur, y ampliando la extensión que abarcaba y pluralizándose como 'Mares del Sur', se mantuvo hasta el siglo XIX hasta que fue desplazado por Océano Pacífico (Jules Marcou, Nuevas investigaciones sobre el origen del nombre América (UNESCO: Biblioteca Digital, 1888).
}

12 Escribe Hernán Cortés: «Entre la relación que de aquellas provincias hizo, trajo nueva de un buen puerto que en aquella costa se había hallado, de que holgué mucho [...] y asimismo se trajo relación de los señores de la provincia de Cihuatán, que se afirman mucho haber una isla toda poblada de mujeres, sin varón alguno, y que en ciertos tiempos van de la tierra firme hombres, con los cuales han acceso, y las que quedan preñadas, si paren mujeres, las guardan, y si hombres, los echan de su compañía; y que esta isla está diez jornadas de esta provincia y que muchos de ellos han ido allá y la han visto. Dícenme asimismo que es muy rica de perlas y oro; yo trabajaré, en teniendo aparejo, de saber la verdad y hacer de ello larga relación a vuestra majestad». Hernán Cortés, Cartas y documentos (México: Porrúa, Sepan Cuántos 3, 1969), 137. 
habitado por las mujeres que morían de parto (cihualpipiltin) y que con un guerrero en el vientre acompañaban al sol en su trayectoria hacia el poniente. ${ }^{13}$

Para la década de 1530, tales eran los prodigios que se contaban, que el propio Cortés organizó la exploración del Mar del Sur, desembarcando, en 1535, en la actual bahía de La Paz y la llamó Tierra de la Santa Cruz, de lo cual informó al emperador. ${ }^{14}$ Entre las numerosas riquezas que ofrecía el lugar, hubo unas que particularmente llamaron su atención y que eran muy valoradas en las Cortes Españolas: las perlas, con las que los propios naturales adornaban su cuerpo y que, pocos años adelante, motivarían expediciones para su explotación en el Mar de Cortés, Mar Bermejo o Golfo de California. A este punto, todos quedaron convencidos y maravillados de haberse topado propiamente con la California de las Sergas. Se dice que la ola de calor que Cortés experimentó al llegar a la zona, le hizo exclamar en latín Callida Formax, lo cual contribuyó a establecer el nombre de California, que iba cobrando fuerza, de modo que para 1540 ya se había generalizado entre los hombres de mar, cartógrafos y capitanes próximos a las expediciones de Cortés.

Pero el nombre de California venía de más atrás: Cristóbal Colón en el Diario de su primer viaje (1494), describe una región similar:

Dijéronle los indios que por aquella tierra hallaría la isla de Matinino, que dizque era, poblada de mujeres sin hombres... y que cierto tiempo del año venían los hombres a ellas de la dicha isla del Caribe, que dizque estaba a diez o doce leguas, y si parían niños enviábanlos a la isla de los hombres y si niñas dejábanlas consigo $[\ldots] . .^{15}$

Con la salvedad de que Cristóbal Colón, lector de las Sergas, decidió cambiar Matinino por California. Y aún hay otro antecedente más

\footnotetext{
13 Véase Miguel León-Portilla, Cartografía y crónicas de la Antigua California (México: UNAM-Fundación de Investigaciones Sociales, A.C., 1989), 38; Antonio Ponce Aguilar, «Origen de la palabra California» (Lecturas Hispánicas, http://barricadaletrahispanic.blogspot.com/2011/09/origen-de-la-palabra-california-antonio.html). Consultado el 23 de marzo del 2020.

14 «Cuarta carta de Relación», en Cortés, Cartas y documento, 191-192.

15 Ponce Aguilar, «Origen de la palabra California».
} 
antiguo, el del Cantar de Rolando, poema épico del siglo XI escrito en francés antiguo y referido a las batallas de Carlomagno en el siglo VIII, que seguramente formó parte de las lecturas de Cortés, pero también de Colón. En él, los estudiosos, particularmente Edward Everett Hale (1822-1909), han identificado en la estrofa CCIX el nombre de California: «las tribus de África, y los de Califerne», ubicando la región al norte de África, mencionadas en el contexto de las palabras de Carlomagno frente al dolor que siente por la muerte de Rolando quien lo defendiera de los contrincantes que lo atacaron por la retaguardia. ${ }^{16}$

El descubrimiento de la relación entre el nombre de California y el Cantar de Rolando se le atribuyó al anticuario Edward Everett Hale (1822-1909), quien en 1864, además, identificó el nombre California con el mundo musulmán, específicamente con el nombre de un dirigente de la comunidad islámica. Años después, en torno a 1917, Ruth Putnam (1856-1931) relaciona los nombres de California y el de la Reina Calafia con Khalifa, del árabe, que también remite a líder, de donde deriva Khilifath, así, California pudiera significar «la tierra del Califa». ${ }^{17}$

De tal modo, el imaginario inicial de California fue el de una isla ubicada al oeste del que fuera el Mar de Cortés (Golfo de California). Por otra parte, resulta muy interesante hacer hincapié en que la referencia a la isla poblada de mujeres y con riquezas sin fin se repitió, coincidentemente y casi en los mismos términos, a lo largo de la literatura épica medieval y de los relatos de los exploradores y conquistadores del siglo XVI.

\footnotetext{
16 «Ami Rollant, prozdoem, juvente bele, / Cum jo serai a Eis, em ma chapele, / Vendrunt li hume, demanderunt noveles; / Jes lur dirrai, merveilluses e pesmes: / "Morz est mis nies, ki tant me fist cunquere". / Encuntre mei revelerunt li Seisne, / E Hungre e Bugre e tante gent averse, / Romain, Puillain e tuit icil de Palerne / E cil d'Affrike e cil de Califerne [...]» (Estrofa CCIX, Les Textes de la Chanson de Roland I (Manuscrit d'Oxford, 1090). Éd. Raoul Mortier, Paris, 1940. Bibliotheca Augustana, https://www.hsaugsburg.de/ harsch/gallica/Chronologie/11siecle/Roland/rol_ch05.html [consultado el 21 de junio del 2020]. Negrita de la autora.
}

17 Véase https://es.qwe.wiki/wiki/Etymology_of_California [Consultado el 12 de abril de 2020]. 


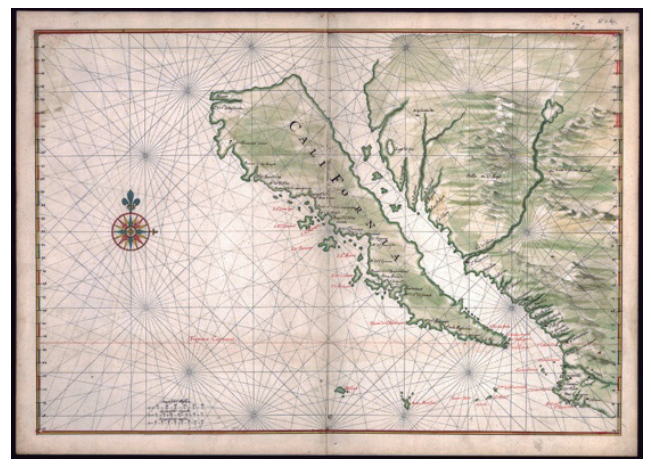

Figura 3. J. Vinckeboons, Joan, Mapa de California como isla (ca.1650).

En http://hdl.loc.gov/loc.gmd/g3291s.mf000074

Por lo demás, lo extremo de su posición geográfica, aunado al imaginario de la época permeado por la cristiandad y entramado con las historias de caballería, ofrecía la sensación de que en California se habría llegado a los confines de la tierra; la propia condición desértica y extrema de su clima, propia del noroeste del país, era propicia para conjeturar que los evangelizadores habían llegado al mejor lugar para llevar a cabo la tarea misional entre los aborígenes: la aridez, la carencia de vegetación alguna, la falta de agua, remitían al lugar de las pruebas y las tentaciones donde los evangelistas habían ubicado, ancestralmente, las luchas contra Satán; se estaba en los límites, donde la tierra se acababa, y habría que hacer acopio de virtudes y entereza para enfrentar las adversidades, las carencias de todo tipo. ${ }^{18} \mathrm{Y}$ si bien se trataba de una tierra remota, del 'último rincón del mundo', no por ello perdía su condición mítica; al contrario, se enriquecía con los atributos que le dieran los misioneros como el lugar de la prédica idónea para rescatar a los aborígenes de la infidelidad.

En parte esto es lo que resguardaría la memoria colectiva del lugar, si bien en el curso de los años se fue redefiniendo el territorio: hacia 1773 la Antigua California se dividió en dos regiones: la Alta o Nueva California y la Vieja California, situación que se mantuvo hasta 1787. Uno de los cambios definitivos vendría con la guerra con Estados

\footnotetext{
${ }^{18}$ Salvador Bernabeu Albert, «California. O el poder de las imágenes en el discurso y las misiones jesuitas», Contrastes 12 (2001-2003): 182-183.
} 
Unidos (1846-1848), con la que se perdió la mitad del territorio mexicano, entre ello, la Alta California, que, en adelante, solo sería nombrada California, en tanto que la parte mexicana sería la Baja California, a su vez dividida en el territorio del norte y el del sur.

\section{EN TORNO AL RECONOCIMIENTO DEL CUERPO DE LA PENÍNSULA}

Pero no bastó con las historias maravillosas que se construyeron a partir de los imaginarios en torno al nombre de California... También el trazado de sus sucesivos mapas tendría mucho qué decir: las míticas leyendas relacionadas con California se proyectaron en los ires y venires de su cartografía.

Si bien desde muy temprano, en los primeros mapamundi de los siglos XIV-XV, la región quedaría dibujada como una península, en los siglos sucesivos oscilaría entre su representación como península o bien como isla, lo cual daría lugar a dos grupos de mapas, según la ubicaran como una o como otra.

Cartografiar la región no fue fácil; además de las circunstancias reales, había que batallar con los imaginarios en torno a la región que la representaban como una de las islas paradisíacas, ubicadas hacia el extremo nororiental de la Nueva España. Fue California, y no la Nueva España, la que desencadenó la imaginación de navegantes y exploradores, cosmógrafos y cartógrafos: alrededor de ella se tejían historias fantásticas relacionadas con los legendarios reinos de Quiviria, Tíguez, las Siete Ciudades de Cíbola, e incluso los dominios bíblicos tales como Tarsis y Ofir ricos en oro, plata y marfil. También pesaba sobre la imaginería popular el tan buscado Estrecho de Anián, como el posible canal entre los continentes entonces conocidos y, más adelante, como la posibilidad de que Asia y América estuvieran conectadas. ${ }^{19}$

Es así como algunos de los antiguos cartógrafos comenzaron a incluir representaciones del territorio en su condición de una enorme isla o bien de península, como sucedió con los mapamundis del siglo XVI publicados

\footnotetext{
19 León-Portilla, Cartografía y crónicas, 1-33; Dora Polk, The island of California: A history of the myth (Washington: University of Nebraska Press, 1991); Glen McLaughlin y Nancy Mayo, The mapping of California as an island: an illustrated checklist (Saratoga: California Map Society, 1995).
} 
por Battista Agnese (Venecia, 1542), Abraham Ortelius (Amberes, 1570), Rumold Mercator (Génova, 1587) y Petrius Plancius (Amsterdam, 1596), entre otros. Pero California, desde la perspectiva de la cartografía moderna, iría ganando en precisión a partir de los informes de los navegantes y conquistadores que se aventuraban a ese mundo y de los cartógrafos que se nutrían de ello planteando otras propuestas a las que hicieran los primeros exploradores, desbordados por las fantasías de la literatura medieval con la que se habían nutrido.

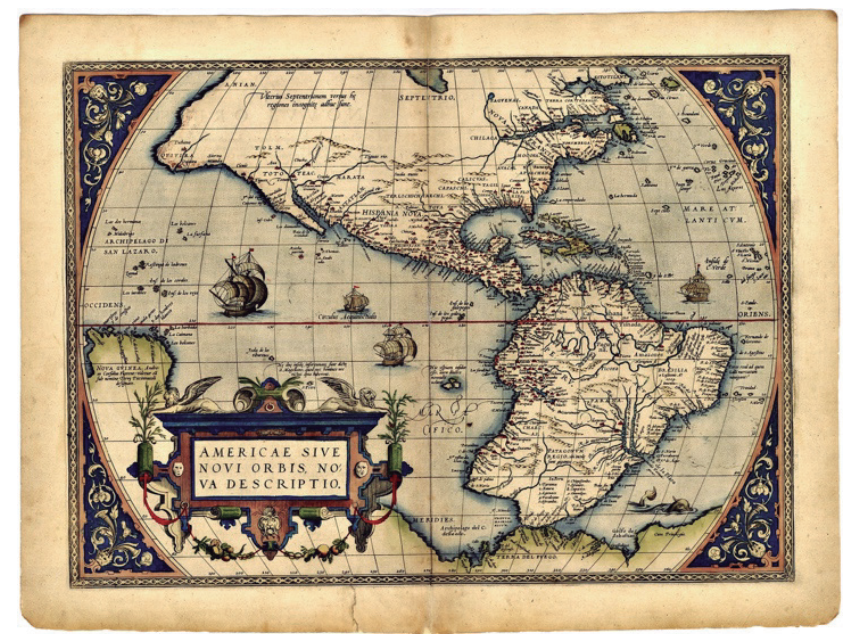

América "Novi Orbis" de Abraham Ortelius (1570).

Figura 3. América «Novi Orbis» de Abraham Ortelius (1570).

En http://valdeperrillos.com/books/bibliograf-recursos-digitales-sobre-cartograf-mapas-antiguos (consultado el 26 de julio del 2019).

California seguiría representándose como el edén mítico, como los lugares imaginados desde muchos siglos atrás, donde se perdía el lindero entre la fantasía y la realidad. El marinero griego Juan de Fuca (1536-1602), al servicio de Felipe II, al explorar la costa oriental del norte quiso ver en ella el buscado Estrecho de Anián, una de las claves universales de la baja edad media que ayudarían a resolver vías de acceso entre los tres continentes conocidos en ese entonces, de modo que pudieran transportar riquezas y mercancías a salvo del asedio de piratas y flotas enemigas con quienes se disputaban el dominio de los mares. Desde los tiempos de Marco Polo (siglo XIII) se pensó en su existencia y, por tradición oral, se transmitió entre las sucesivas 
generaciones de navegantes ${ }^{20}$ que no tenían elementos para verificarlo. De algún modo el mito, ubicado en el río Ania, al este de la India, se desplazó al norte del Nuevo Mundo ubicándose en la zona de la California. ${ }^{21}$ Esto representaba para España descubrir un estrecho que abriría el paso franco entre sus dominios. Por su parte, el propio Virrey de Mendoza de la Nueva España, en torno a 1540, en cuanto pudo envió expediciones para explorar la zona, convencido de encontrar las míticas ciudades de Cíbola y Quivira que concentraban una parte importante de las riquezas anheladas.

Ahora bien, si en antiguos mapamundi California se había representado como península, ¿dónde comenzó el error?

Hubo voces que se lo atribuyeron al corsario inglés Sir Francis Drake (1540-1596) quien, en nombre de Inglaterra, tomó posesión de ella en 1577-1579, con el nombre de Nueva Albión:

Algunos Cosmógrafos antiguos, aunque con algunas imperfectiones, pintavan la California hecha Penisla o Ystmo, pero desde que el pirata y piloto Francisco Draque navegó por estos mares y en su bahía de San Bernabé, cerca del cabo de San Lucas, de la California, robó el navío de China o galeón de Filipinas llamado Santa Ana [...]; viendo entonces las muchas corrientes del brazo de mar de la California, discurrió y divulgó por cosa cierta que este Seno y Mar Califórnico tenía comunicación con el mar del Norte, y la pintó cercada de mares y Isla (que hubiera sido la mayor del mundo) [...] Draque de vuelta a sus tierras engañó a toda la Europa, y casi todos los Cosmógrafos y Geógrafos modernos de Italia, Alemania y Francia pintaron la California isla. ${ }^{22}$

Sin embargo, esta distorsión, que se prolongaría a lo largo de casi cien años, no es atribuible del todo a Drake ni se trata solo de los corsarios ingleses, porque hubo otros muchos al servicio del imperio británico que engrandecieron el esplendor de la Reina Elizabeth con sus

\footnotetext{
${ }^{20}$ Dora Polk, «Chapter 1. Fifteenth-Century Mariners Inhert Medieval Myths», en Polk, The island of California, 119-132.

${ }^{21}$ León-Portilla, Cartografía y crónicas, 17; Polk, The island of California.

${ }^{22}$ Eusebio Kino, Crónica de la pimeria alta: Favores celestiales (Hermosillo, Sonora, México: Gobierno de Sonora, 1985): 155-156.
} 
descubrimientos echando por tierra los límites de la Terra Incognita. La cuestión es más compleja: se trata de la avanzada de la expansión territorial y los imperios en pugna por conquistar lejanas regiones, atravesada por las culturas de la época y mediada por la contienda entre reformadores y contrarreformadores, entre el Imperio Británico y el Español.

En el caso de los españoles, el primero en llegar a California en 1534, enviado por Cortés en 1533 en el segundo viaje de exploración, fue Fortún Ximénez, quien imaginó que se trataba de una isla. ${ }^{23} \mathrm{~A}$ partir de los informes y las maravillas que ahí se consignaban, en 1535, el propio Hernán Cortés (1485-1547) incursionó hacia el Mar del Sur; para él, California era una isla que respondía al imaginario de la época, pero su expedición fracasó. ${ }^{24}$

Más tarde, en 1539, Cortés envió al navegante Francisco de Ulloa (? - 1540) a explorar las costas del Mar Pacífico, quien hizo algunos registros de las islas, recorrió el Mar Bermejo (Golfo de Cortés) y se dio cuenta de que la zona no era una isla; su piloto Domingo del Castillo trazó algunas cartas geográficas al respecto. Por su parte, Hernando de Alarcón (1500-1541) continuó las exploraciones de Ulloa navegando por el extremo del Golfo de California hasta incursionar aguas arriba en lo que será el río de Nuestra Señora del Buen Guía (hoy Río Colorado) hasta coincidir con el Río Gila cayendo en la cuenta de que no estaba abierto el paso por agua entre el Golfo de California y el Mar del Sur, como era propio de una península, no de una isla (1541). El hallazgo se confirmó en distintas expediciones realizadas sucesivamente en el curso de los siglos XVI y XVII por españoles, como Juan Rodríguez de Cabrillo (1542) y Francisco de Ortega (1631) entre otros, y por corsarios holandeses e ingleses, lo cual confirmaba la peninsularidad del territorio.

\footnotetext{
${ }^{23}$ Véase John W. Caughey, California (Englewood: Prentice-Hall, 1953), 45-46; Ch. Chapman y E. Charles, A History of California: The Spanish Period (New York: The MacMillan Co., 1921), 50-51. En el segundo viaje de exploración, enviado por Cortés en 1533 hacia los Mares del Sur, partieron dos naves, Concepción, a cargo de Diego Becerra, donde venía Fortún Ximénez, y San Lázaro, a cargo de Hernando de Grijalva. Fortún traicionó y asesinó a Becerra y, desplazándose hacia el noroeste llegó a la Bahía de lo que será La Paz, convencido de que era una isla, con las riquezas y exuberancia que se habían imaginado desde algunos años antes, mediada por el aguerrido encuentro con los aborígenes. Fantasía y realidad se empalmaban nuevamente.
}

${ }^{24}$ Polk, The island of California, $274 \mathrm{y}$ ss. 
Es a principios del siglo XVII cuando esta versión se desvía: el fraile carmelita Antonio de la Ascensión, integrado a la flota de Sebastián Vizcaíno, hacia 1602 volvió a trazar el mapa de California como isla lo cual hizo que resurgiera el error que para ese entonces ya estaba superado.

El reconocimiento de la peninsularidad de California, en los primeros años del siglo XVIII, le correspondió a Eusebio Kino (16451711), jesuita destinado a las Misiones del noroeste de México, en la zona que hoy ubicamos como California, norte de Sonora, norte de Sinaloa y sur de Arizona. Él era originario del norte de la Península Itálica — cuando la región estaba configurándose- y una parte importante de su formación había transcurrido en la Universidad de Friburgo y en la Universidad de Ingolstadt, en contacto con excelentes versados en geografía y cartografía, como Henricus Scherer (1628-1704) y Adamo Aygentler (1633-1673), a través de los cuales tuvo acceso a interesantes mapas que trazaban la imagen del mundo de la época, en los que se incluía California:

En la insigne Universidad de Ingolstadio de Baviera imprimió en mi tiempo un muy curioso Mapa Universal de todo el mundo terráqueo, mi Padre Maestro de Matemáticas, el P. Adamo Aygentler [...]. Este mapa que lo truxe conmigo a las Indias y hasta a estas Nuevas Conversiones, con su tratadito e instrucción o explicanda, pues es cosmográfico, geográfico, horólogo y horográfico y naútico y geométrico \&, pone muy bien la California, no isla, sino penisla $[\ldots] .25$

Kino, además, traía un buen bagaje de Matemáticas como estudiante destacado en este campo, lo cual no era inocuo para las tareas que habría de acometer: las Matemáticas, para el siglo XVII estarían estrechamente vinculadas con la nueva ciencia y con los problemas que se avizoran frente a los programas de expansión, de exploración y conocimiento de nuevos territorios. En ellas se ubicaba la cosmografía, con las vertientes de astronomía, como ciencia de los cuerpos celestes, que conducía a fijar con mayor exactitud su movimiento y el curso de los astros, así como de geografía, o ciencia de la esfera terrestre, vinculada con las

${ }_{25}$ Kino, Crónica de la pimeria alta, 156. Se refiere a la Tabula Geographico Horologa Universalis: Problematis Cosmographicis, Astronomicis, Geographicis, Gnomonicis, Geometricis Illustrata: Et Una Cum Succincta Methodo Quaslibet Mappas Geographicas Delineandi (1668), de Adam Aigenler. 
posibilidades de localizar con exactitud los lugares y representarlos a través de mapas. ${ }^{26}$

De modo que Kino, provisto con la Tabula Geographico-Horologa de su maestro A. Aygentler, con sus instrumentos de cartografiar (aguja de marear, compás, astrolabio, anteojo de larga vista) y con un conocimiento profundo de las Matemáticas, llegó a las Indias Occidentales convencido de la peninsularidad de California, pero, era tal la fuerza de la creencia generalizada que ya desde su primer acercamiento a la zona, enviado por el virrey de la Nueva España (1683-1684) con el grupo coordinado por el Almirante Isidro Atondo, Kino se refiere a «esta grandísima isla [...] casi otra Nueva España en el tamaño»,27 y así la empezó a dibujar publicándola bajo el título de Relación Puntual de la entrada que han hecho los Españoles en la grande isla de la California, este año de 1683.

Otro de los mapas muy reconocidos de Kino, siempre desde la perspectiva de la insularidad de California, figura en Los trabajos apostólicos de la Compañía de Jesús en la América Septentrional (1695-1696), mapa muy conocido en Europa que, por distintas circunstancias, llegó a París, a manos de Claude Delisle (1644-1720), cartógrafo del Rey de Francia, admirado por la calidad del trabajo y por la información ahí se proporcionaba sobre lugares desconocidos. ${ }^{28}$ Se llegó al extremo de plagiarlo con el nombre del geógrafo y cosmógrafo Nicolás de Fer (1646-1720) y publicarlo en sucesivas ocasiones.

\footnotetext{
${ }^{26}$ Horacio Capel, «La geografía como ciencia matemática mixta. La aportación del círculo jesuítico madrileño en el siglo XVII», Geo Crítica. Cuadernos críticos de geografía humana V, n. ${ }^{\circ} 30$ (1980): 1 .

${ }_{27}$ W. Mathes, Californiana, vol. III, t. II, documento 25, 330-331, apud. Marcelo Ramírez Ruíz, «El método cartográfico del Padre Kino: "Con la aguja de marear y astrolabio en la mano" a través de los paisajes de California y del noroeste novohispano», en José Carlos Zazueta Manjarrez (coord.), Seminario La religión y los jesuitas en el noroeste nonohispano, V, coord. José Carlos Zazueta Manjarrez (México-Sinaloa: El Colegio de Sinaloa, 2012): 92.

28 «Delisle a Regis, Comentario acerca del mapa de Kino", Teatro de los trabajos, 1700, Apud. Herbert Eugene Bolton, Los confines de la cristiandad. Una biografía de Eusebio Francisco Kino, S. J., misionero y explorador de Baja California y la Pimería Alta (México: Universidad de Sonora, Universidad Autónoma de Baja California, Universidad de Colima, Universidad de Guadalajara, Colegio de Sinaloa, Editorial México Desconocido, 2001), 680 (Trad. Felipe Garrido). En Bolton se pueden seguir las historias relacionadas con el plagio de los mapas de Kino.
} 


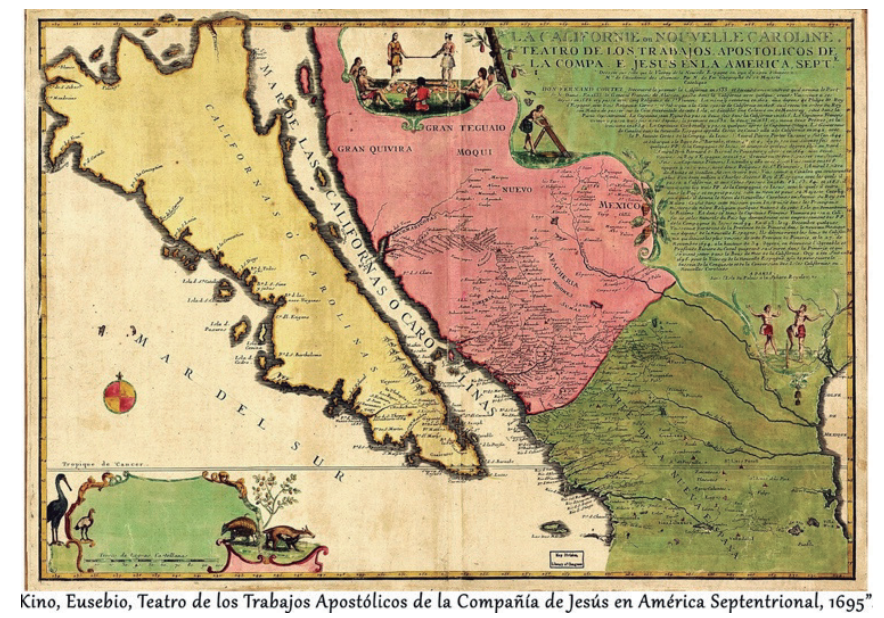

Figura 4. Eusebio Kino, Teatro de los Trabajos Apostólicos de la Compañía de Jesús en América Septentrional, 1695. En https://commons.wikimedia.org/wiki/File:Martirio_de_Francisco_Xavier_

Saeta.png?uselang=es (consultado el 15 de noviembre de 2019).

Pero el mapa, fruto de sus observaciones y mediciones reales siguiendo el curso de la desembocadura del río Gila en el Colorado entre 1696 y 1702, que marcó definitivamente la historia de la cartografía regional y universal fue la obra Paso por tierra á la California y sus confinantes Nuevas Misiones de la Compañía de Jesús en la América Septentrional. Paso por Descubierto, andado y remarcado por el Padre Francisco Kino, jesuita, desde el año el 1698 y hasta el de 1701 (manuscrito, 1701), cuyo propósito fue demostrar la peninsularidad de la California, que a su vez fue impreso sucesivamente en París, Berlín y Londres, entre otros lugares.

Curiosamente, uno de los supuestos de Kino para retornar a la perspectiva de la peninsularidad de las Californias, por increíble que pudiera parecer, fue detectar la zona de la que procedían las conchas azules iridiscentes de las que también podrían obtenerse perlas..$^{29}$ Estas procedían

\footnotetext{
${ }^{29}$ Desde tiempos antiguos las perlas, junto con otras piedras preciosas, han sido percibidas con grandes atributos que las volvieron objetos codiciables, dignos de poseerse. En el caso de las regiones recién descubiertas, fue una constante el indagar su existencia con los habitantes originarios, de tal modo que las perlas tuvieron una larga y accidentada historia en la región californiana: desde las primeras exploraciones del siglo XVI se supo de su existencia en lo que sería el Mar de Cortés, las habían visto como adorno de los naturales y supieron dónde se encontraban los bancos. Al despertar las ambiciones de exploradores y conquistadores fueron motivo de explotación hasta
} 
de la costa de la California que daba directamente cara al Océano Pacífico y que Kino había conocido durante sus primeras expediciones con el Almirante Isidro Atondo y Antillón, encargado de la primera fase de colonización y evangelización de los naturales californianos. Poco tiempo después, ya durante sus propias incursiones en pos de la peninsularidad de la California, los indios del río Colorado las obsequiaban a quienes entraban en contacto con ellos y establecían buenas relaciones; llegó, incluso, a reunirse con pimas, copas y cocomaricopas para constatar su origen, lejos de la costa más próxima al Mar de California, lo cual hacía suponer que existía un paso por tierra y no directo entre los dos mares. Kino continuó recogiendo información en otros poblados al respecto:

[...] juntamente con continuados varios exámenes acerca de las conchas azules que se traían del Nordueste y de los Yumas y Cutganes, que conocidamente venían de la contracosta de la California y de aquella mar a diez o doce días de camino más remota que esta otra mar de la California, en la cual hay conchas de nácar y blancas, y otras muchas, pero no de aquellas azules que nos dieron los Yumas y me enviaron con la santa cruz a Nuestra Señora de los Remedios. ${ }^{30}$

De modo tal que, para las intuiciones de Kino, el misterio de las conchas azules y la búsqueda del paso por tierra a la California, quedarían indisociablemente unidos y la asociación resultó acertada.

Pues bien, para Kino fue verdaderamente emocionante el momento en que logró ver el brazo de mar y el paso por tierra; descubrir que la California, en efecto, era una península y no una isla, y esta era la primera evidencia:

[...] el año de 1698, en treinta y uno grados de altura, a las 105 cinco leguas de distancia de nuestra Señora de los Dolores, rumbo del Nordueste, en el muy alto cerro o antiguo volcán de Santa

\footnotetext{
que se fue normando esta actividad y dando concesiones para ello desde el gobierno de la Nueva España; sin embargo, la pesca de perlas siempre constituyó un asunto conflictivo, situación que los misioneros trataron de proteger de la soldadesca (Salvador Bernabéu Albert, «Perlas para la reina. Aportaciones para el estudio de la industria perlífera en la Nueva España (1790-1809)», Estudios de Historia Novohispana, 15 (2015): 130-132.
}

${ }^{30}$ Kino, Crónica de la pimeria, 97. 
Clara, devisé patentísimamente, con anteojo y sin anteojo, el encerramiento destas tierras de la Nueva España y de la California y el remate dessa Mar de la California y el passo por tierra que en 35 grados de altura havía. Pero por entonces no lo concebí por tal, y me persuadía que más adelante y más al Poniente subiría esa mar de la California a más altura hasta a comunicarse con la Mar del Norte o estrecho de Anian, y dexaría y haría isla a la California $[\ldots] \cdot{ }^{31}$

No obstante, aún habrían de sucederse otras expediciones, años de por medio, muchas leguas de camino a caballo para ratificar, de manera definitiva, su descubrimiento. Además, no solo habló con distintos grupos de indios de la zona, sino que no conforme con sus propias observaciones, constatadas con los compañeros de cada expedición, enviaba cartas y relaciones a varias personas e invitaba a autoridades, como a Fray Manuel de Oyuela y Valverde, quien lo transmitió a la Corte, solicitándoles la confirmación in situ, o a través de informes que lo atestiguaran. También obtuvo el testimonio del Capitán Manje, con quien realizó algunas expediciones a lo largo de ocho años. ${ }^{32}$

Ahora bien, ¿por qué tal interés por encontrar el paso por tierra a la California? ¿Cuál podría haber sido el significado de que California fuera una isla o bien una península?

A Kino, como misionero, le preocupaba tender un puente entre la Pimería Alta (actual Sonora, Sinaloa y sur de Arizona) y la California, de modo que la una abasteciera a la otra y posibilitara el desarrollo de sus poblados hasta que lograran autosuficiencia. Su propósito fundamental era la difusión del credo católico, aunque también visualizaba las riquezas terrenales que la región representaba para la corona española (desde tiempos de Hernán Cortés era muy valorada la producción de perlas, el 'oro de los tontos', el petróleo, los minerales). ${ }^{33}$

\footnotetext{
${ }^{31}$ Kino, Crónica de la pimeria, 92-93.

32 Kino, Crónica de la pimeria, 359. También «Testimonio del Capitán Manje» y «Elogio del Padre Kino por el Capitán Manje», en Ernest Burrus, La obra cartográfica de de la Provincia Mexicana de la Compañia de Jesús, 1567-1767, I. (Madrid: José Porrúa Turanzas, 1978), 167-170 y 193-194 respectivamente.

${ }_{33}$ Kino, Crónica de la pimeria, «Capítulo XI. Utilidades que se podrán seguir destas Nuevas Conversiones en abono de toda esta Septentrional incógnita América», 171-172.
} 
Para el misionero jesuita el mapa era su instrumento de trabajo, y desde ahí ayudó a que la península de California transitara de la zona mítica de los relatos de la alta Edad Media, de la del embeleso renacentista por los islarios, a una representación más cercana a la realidad, sin dejar por ello de tener un halo de fantasía y sueños quiméricos en la memoria colectiva de los californianos.

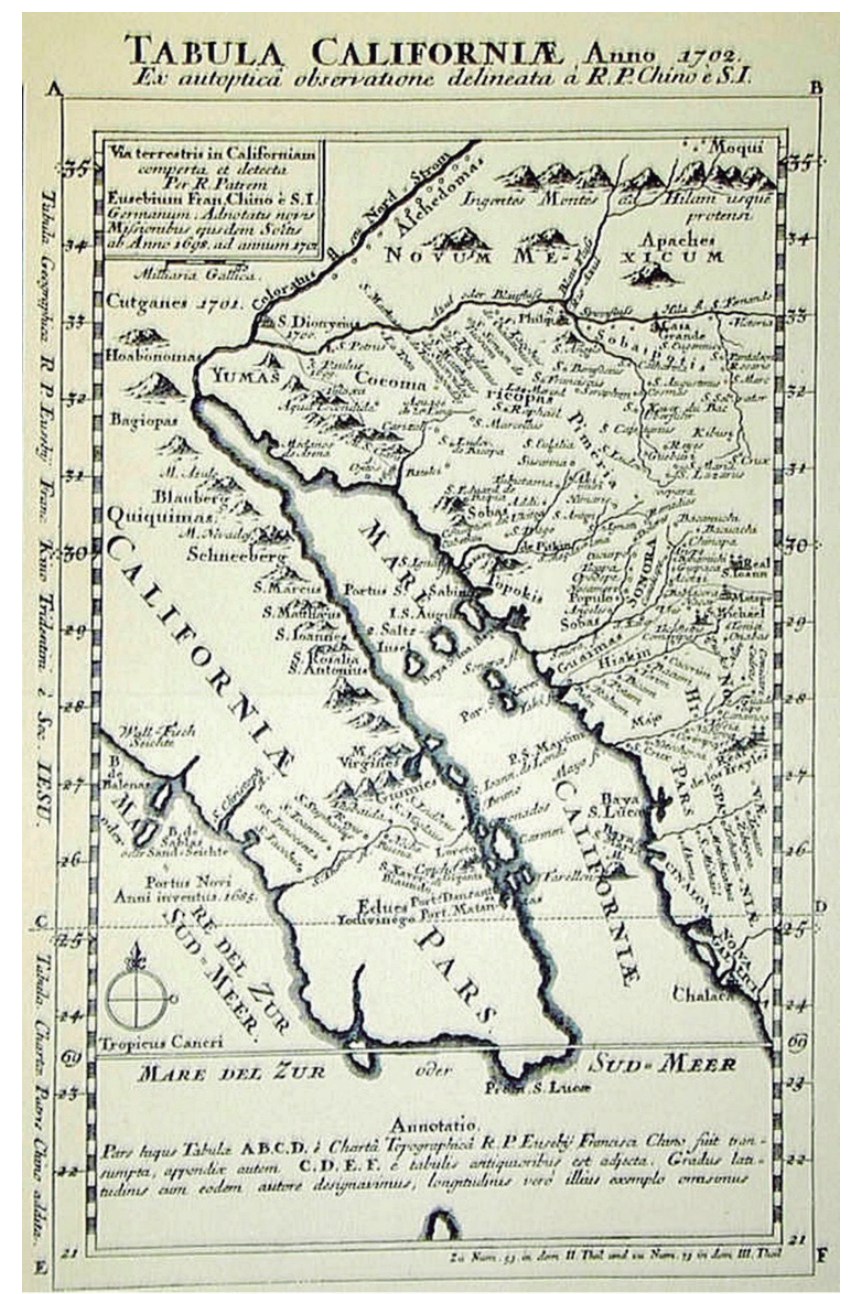

Kino, Eusebio, Tabula Californiae, Anno 1702.

Figura 5. Eusebio Kino, Tabula Californiae, Anno 1702.

En https://exhibits.stanford.edu/california-as-an-island/catalog/qt320qh7523.

Consultado el 12 de septiembre de 2019. 


\section{A MODO DE CIERRE}

Si los movimientos de renovación historiográfica han desplazado el lugar del conocimiento positivo, objetivo, al reconocimiento de la intervención de los sujetos en la producción de conocimiento, a su mediación en la construcción de los saberes a partir de su experiencia, sus legados, su cultura, su tiempo, en realidad estamos hablando del movimiento paradigmático que nos compete a todos, que tiene múltiples expresiones en los distintos campos del conocimiento. La Geografía, sus formas de transmisión, no pueden ser ajenas a ello.

Así, reconociendo que la Geografía es un campo que participa de la dimensión propia de los saberes científicos y de los saberes humanísticos, se revela que el espacio, y por ende el territorio, en sus múltiples dimensiones, calas y densidades, es, sin lugar a dudas, una construcción socio-cultural sujeta a sucesivas transformaciones y desplazamientos en el curso del tiempo, que desbordan el terreno de lo concebido como 'natural'.

En este sentido, la proximidad y articulaciones entre toponimia y cartografía, en una perspectiva de largo aliento aportan claves importantes sobre el significado de los procesos de configuración del territorio, lo cual hace de ambas excelentes recursos para comprender sus sucesivas transformaciones y desplazamientos, mediados por dimensiones sociales, históricas y culturales. Se trata de recursos susceptibles de explotarse, en el más amplio sentido de la palabra, desde una mirada crítica, en los distintos espacios formativos relacionados con este campo de saberes.

\section{Nota sobre la autora}

María Esther Aguirre Lora es investigadora titular en el Instituto de Investigaciones sobre la Universidad y la Educación, UNAM (México). Pertenece al Sistema Nacional de Investigadores, nivel 3 (CONACyT); obtuvo el reconocimiento Premio Universidad Nacional en el área de investigación en Humanidades (UNAM, 2011). Principales líneas de investigación: 1) Desplazamientos paradigmáticos en el campo de la historia de la educación; 2) Historia social y cultural de la educación artística. Estudios de doctorado en educación y diplomado en Historiografía 
francesa. Publicaciones recientes: Narrar historias de la educación. Crisol y alquimia de un oficio (UNAM-IISUE, 2016), Campo 9, Historia e historiografía de la educación en México. Hacia un balance 2002-2012, 2 vols. (COMIE-ANUIES, 2016), Modernizar y reinventarse. Escenarios de la formación artística ca. 1920-1970 (UNAM-IISUE, 2017), Pioneros de las ciencias y las artes. Travesías culturales entre la Península Itálica y la Nueva España, siglos XVI al XVIII (UNAM-IISUE, 2020).

\section{REFERENCIAS}

Aguirre Lora, María Esther. Pioneros de las ciencias y las artes. Un estudio de los circuitos culturales entre la Península Itálica y la Nueva España, siglos XVI al XVIII. México: UNAM-IISUE, 2020.

Arenas Martija, Andoni y Víctor Salinas Silva. «Giros en la educación geográfica: renovación de lo geográfico y lo educativo». Revista de Geografía Norte Grande 56 (2013): 143-162.

Bedoya, Eduardo. «Toponimia: Herencia cultural». Revista Herencia 19, no. 1 (2006): 9-31.

Bernabéu Albert, Salvador. «California. O el poder de las imágenes en el discurso y las misiones jesuitas». Contrastes 12 (2001-2003): 159-185.

Bernabéu Albert, Salvador. «Perlas para la reina. Aportaciones para el estudio de la industria perlífera en la Nueva España (1790-1809)». Estudios de Historia Novohispana 15 (2015): 129-158.

Bolton, Herbert Eugene. Los confines de la cristiandad. Una biografía de Eusebio Francisco Kino, S. J., misionero y explorador de Baja California y la Pimería Alta, México: Universidad de Sonora, Universidad Autónoma de Baja California, Universidad de Colima, Universidad de Guadalajara, Colegio de Sinaloa, Editorial México Desconocido, 2001. Trad. Felipe Garrido.

Burrus, Ernest J. La obra cartográfica de la Provincia Mexicana de la Compañía de Jesús, 1567-1767, I. Madrid: José Porrúa Turanzas, 1978.

Caughey, John W. California. Englewood: Prentice-Hall, 1953, 2. ${ }^{\text {a ed. }}$

Capel, Horacio. «La geografía como ciencia matemática mixta. La aportación del círculo jesuítico madrileño en el siglo XVII». Geo Crítica. Cuadernos críticos de geografía humana V, n. 30 (1980): 1-35.

Chapman, Charles E. A History of California: The Spanish Period. New York: The MacMillan Co., 1921.

Cortés, Hernán. Cartas y documentos. México: Porrúa, Sepan Cuántos 3, 1969. 
«Etymology of California». En https://es.qwe.wiki/wiki/Etymology_of_California [consultado el 12 de abril de 2020].

González Sánchez, Carlos Alberto. Los mundos del libro. Medios de difusión de la cultura occidental en las Indias de los siglos XVI y XVII. Sevilla: Universidad de Sevilla-Diputación de Sevilla, 2001.

Kino, Eusebio Francisco. Crónica de la pimeria alta: Favores celestiales. Hermosillo, Sonora, México: Gobierno de Sonora, 1985. 3. ${ }^{\text {a }}$ ed.

León-Portilla, Miguel. Cartografía y crónicas de la Antigua California. México: UNAM-Fundación de Investigaciones Sociales, A.C., 1989.

Leonard, Irving A. Los libros del conquistador, trad. de Mario Monteforte. México: Fondo de Cultura Económica, Lengua y Estudios Literarios, 1979. 2. ${ }^{a}$ ed.

Marcou, Jules. Nuevas investigaciones sobre el origen del nombre América. www. unesco.org: Biblioteca Digital, 1888.

McLaughlin, Glen and Nancy Mayo. The mapping of California as an island: an illustrated checklist. Saratoga: California Map Society, 1995.

«Memorial del Padre Juan María de Salvatierra a la Real Audiencia de México». $1^{\circ}$ de marzo de 1700. Fondo Misiones Jesuíticas, 3/42.3. Archivo Franciscano, Biblioteca Nacional.

Monmonier, Mark. How to lie with maps. Chicago: University of Chicago Press, 1991.

Mortier, Raoul (ed.). «Les Textes de la Chanson de Roland I», Manuscrit d'Oxford, 1090, Bibliotheca Augustana, Paris, 1940. En https://www.hsaugsburg.de/ harsch/gallica/Chronologie/11siecle/Roland/rol_ch05.html [consultado el 21 de junio de 2020].

Murphy, Brenda L. «From interdisciplinary to inter-epistemological approaches: Con- fronting the challenges of integrated climate change research». Canadian Geographer 55, no. 4 (2011): 490-509.

Ordóñez [Rodríguez] de Montalvo, Garci. Las Sergas del muy virtuoso y esforzado caballero Esplandián, hijo de Amadís de Gaula (Sevilla: Cromberger, 1510).

Polk, Dora. The island of California: A history of the myth. Washington: University of Nebraska Press, 1996.

Ponce Aguilar, Antonio. «Origen de la palabra California», Lecturas Hispánicas. En http://barricadaletrahispanic.blogspot.com/2011/09/origen-de-la-palabra-california-antonio.html (consultado el 23 de marzo del 2020).

Ramírez Ruiz, Marcelo. «El método cartográfico del Padre Kino: "Con la aguja de marear y astrolabio en la mano" a través de los paisajes de California y del noroeste novohispano», en José Carlos Zazueta Manjarrez (coord.), Seminario La religión y los jesuitas en el noroeste nonohispano, V, 63-100. México-Sinaloa: El Colegio de Sinaloa, 2012. 
Rodríguez de Montalvo, Garci y Enrique de Castilla, el Senador. Los cuatro libros del virtuoso caballero Amadís de Gaula. Zaragoza: Jorge Coci editor, 1508.

Rodríguez de Montalvo, Garci. Las sergas del muy virtuoso y esforzado caballero Esplandián, hijo de Amadís de Gaula. Sevilla: Cromberger, 1510.

Santiago Rivera, José Armando. «La enseñanza geográfica tradicional, la renovación pedagógica y didáctica de su práctica escolar cotidiana». Terra 30, no. 48 (2014): 63-81. 